\title{
Development of Decision Support System for Health Care Consultation using RFID Based NFC Tags for Patient Identification
}

\author{
Arshia Zaffar ${ }^{1}$, Mahnoor Gul $^{2}$, Rida Mumtaz ${ }^{3}$ and Aliya Ashraf Khan ${ }^{4}$ \\ E-mail: ${ }^{1}$ arsh_zafar@yahoo.com, ${ }^{2}$ mahnoorgul28@yahoo.com, ${ }^{3}$ ridamumtaz.3@gmail.com, \\ 4aliya_khaan@hotmail.com
}

\begin{abstract}
The paper core idea is to develop a Decision Support System for Health Care Center with primary focus on Patient, Admin and Doctor's authentication using (Radio Frequency Identification) RFID based NFC tags. Paper flow is categorized mainly in four parts. First phase deals with registration and authentication (NFC tags), while the next phase deals with the diagnosis of the diseases based on two Data Mining algorithms NN and BNN. Third phase is about General Check-up of patient in order to examine patient medical history based on heart rate, respiratory rate, sugar level and cholesterol level. Lastly, information about blood donor is kept for facilitating the needy patients. staff to view and update the desired patient's information from hospital system, only by reading the patient's NFC tag.
\end{abstract}

Index Terms - Radio Frequency Identification, Near Field Communication, Neural Network and Bayesian Belief Network.

\section{INTRODUCTION}

Real-time visibility has been provided to the healthcare workers by the introduction of innovative technologies. RFID is an emergent technology in healthcare and is being used for the enhancement of operational processes, facilitate business intelligence and improve health-care outcomes. The project focuses on the development of a technical concept for interactive, decentralized Near Field Communication (NFC) based medication related services. The use of Algorithms in Medical field is gaining popularity in the past few years; they help the doctors in taking decisions. Medical decisions are part of several areas of medical activity including medical test selection, diagnosis, and therapy. The process of attempting to determine or identify possible diseases in a patient is referred to as Medical decision support system. Automated decision support system is a mechanism based on the concept of rulebased systems that are automatically providing solutions to repetitive management problems. Taking Medical decision could be extremely specialized and can prove to be a very difficult job due to alternative factors or in case of rare diseases. However, as it has been clearly specified that the proposed system is going to be a decision support system which means that the results of these algorithms will be considered as helping hand for doctors to quickly predict the diseases.

\section{LITERATURE REVIEW}

Based on survey of several research papers relevant work is organized, which depicts the emergence, and effectiveness of RFID technology in medical world.

A. Devendran et al. [1] proposes a solution for reducing medical errors and enhancing quality of service in healthcare sectors. Patient's record and history are updated electronically on a server and based on these reports doctor prescribes test for future. Additionally, record of x-rays, BLI tests, prescribed doses and other relevant information is also maintained. Medical staff accesses the data via computers. Further, at the time of discharge all the patient's record is saved on NFC tag so that the complete medical record is present with the patient as well. A. Prinz et al. [2] is of view that NFC technology has eased the working of complex tasks by involving simple touch over system. NFC-based mobiles are used that reads the tag and displays the information of the user. Data is stored in a server and can be viewed by medical staff. NFC technology in this paper is embedded in a way that it acts as self-management process for tracking health of heart patients, old-aged or disables patients, who can report their condition directly by filling a questionnaire with the help of NFC-based mobiles. It is assumed that the patient is well aware with the use of NFC-based mobiles.

N. Rahman et al. [3] represents RFID technology as a unique way in Malaysian hospitals for tracking patients, medical equipment's and medicines. Many hospitals of Malaysia utilize RFID based smart phones for laboratory tests. Some of the Malaysia's government hospitals have embedded barcode system for tracking the equipment's by using NFC tags. Pantai Hospital use RFID for registration purpose and for other administration work; like assigning appointments, keeping patient's medical record. The technology therefore enhances reliability, correctness, efficiency, safety and portability of services in health centers.

A. Krishna et al. [4] mentions that many of the hospital across the globe that record patient's medical 
history on papers. From the time of registration till recovery all the reports are updated manually which may possess a high chance of error. In order, to make manual work efficient it is replaced by NFC emerging technology, which automates registration, identification, and tracking of patient's reports and check-ups. NFC unique ID is stored on a chip fix around the wrist in a band form and contains patient's information, which can be accessed by medical staff anytime without disturbing the patient.

T. Cerlinca et al. [5] says RFID technology has stepped into medical field and is used to track patients, equipment and the medical staff. It provides identification by assigning unique ID protected by a password. Further, enhances the overall safety and optimize the manual effort, reduces time and cost. In a hospital located in New York nurses place a RFID band around the patient's wrist that helps in giving timely dose of medicines. A.Devendran et. al. [6] represents mobile channels as means of delivery health. Such systems enhance the quality of patient care without increasing the cost. These services use Near Field Communication (NFC) for the provisioning of healthcare to people anywhere, anytime using mobile phones that are connected through wireless communication technologies. The patient for self-help or to communicate with a professional can use them. The process of patient record keeping is made much more efficient by the use of NFC based Electronic Medical Records (EMR) system.

D. Peter et al. [7] proposed methodology takes advantage of NFC capabilities and intelligent ontology software to provide health professionals with a much more efficient method of delivering treatments to patients. Ontology provides a common terminology that facilitates exchange of knowledge and reusability.

K. Harald et al. [8] discussed openEHR that has been used for the development of mobile ward round system. It is developed to be used on Android platform, which integrates and uses NFC to explore new ways of data processing, computer interaction and workflows in the medical world. The patients will be automatically identified via NFC using the mobile devices. The system uses openEHR platform to store and query data for patients.

Ekahau [9] proposed system refers to Location based Services (LBS). Normally, real-time locating solution (RTLS) and radiofrequency identification (RFID) are used interchangeably. An RTLS solution is a positioning system that pinpoints the location of an object or person indoors and outdoors. It uses active RFID technology to pinpoint location. By adopting RTLS the costs are significantly reduced. By using the right RTLS solution, hospitals can take location data and analyze trends that transform operations.

M. Adam et al [10] represent a generalized system using NFC-enabled mobile phones that tracks and cares for patients in a low-resource setting in Karachi, Pakistan. One of their targeted diseases is pneumonia in young children. To overcome this disease some tools have been developed which utilize NFC-capable mobile phones to allow electronic patient identification and tracking across multiple providers.

Tobias et al. [11] proposed system allows interactive communication between NFC enabled devices for patient's medication related services such as the avoidance of an overdose for mentally ill patients using mobile smart device. An NFC-enabled mobile health care solution is new invention, failing to utilize the various opportunities created by technology.

S.Günter et al. [12] considered NFC as wireless interface that is available in smart phones and it is a mean of communication. M-Health-based system is an NFC based concept that deals with individual Patient suffering from chronic diseases like diabetes; heart failure can keep in touch with system anytime anywhere. Using NFC enabled smart phones is not easy for everyone. Any misconception related to disease may lead to a big failure. Lack of education for NFC enabled mobile devices may cause many problems.

I. Rebeca et al. [13] refers to automatic patient identification system based on graphic codes i.e.1 dimensional and 2 dimensional. 1D represents information in the form of black and white areas, 2D store alphanumeric characters. When patient is admitted to hospital his basic information is printed on bracelet and assigned unique number to them.

June-Suh Cho [14] used RFID and mobile devices in healthcare. When patient comes to hospital he/she is identified with the help of tag and by keeping that tag into his/her pocket and the moments are traced and staff can check his/her progress.. System improves customer's satisfaction. On the other hand RFID tags are expensive adopting such system may not ensure financial justification.

P.Kiran et al [15] represents NFC as better technology than bar-code scanners. Using NFC enabled smart phones or tablets, identification is done. NFC tags are used for patient, doctor and other staff identification in a hospital. With the help of tags doctor can also view patient records, can communicate with staff and patients.

\section{PROPOSED SYSTEM}

\section{(A). Basic System Flow Diagram}

Following diagram shows the working of the system in detail and enlists the sequence that is to be followed for the proper functioning of the system. It includes registration, assigning, authenticating, saving, generating and retrieving reports. And also provides patient history details.

\section{(B). System Diagram}

Given below is the system diagram of the proposed system, which shows the operations that can be performed using the system. The role model to use this system is mainly the admin and the doctors. 


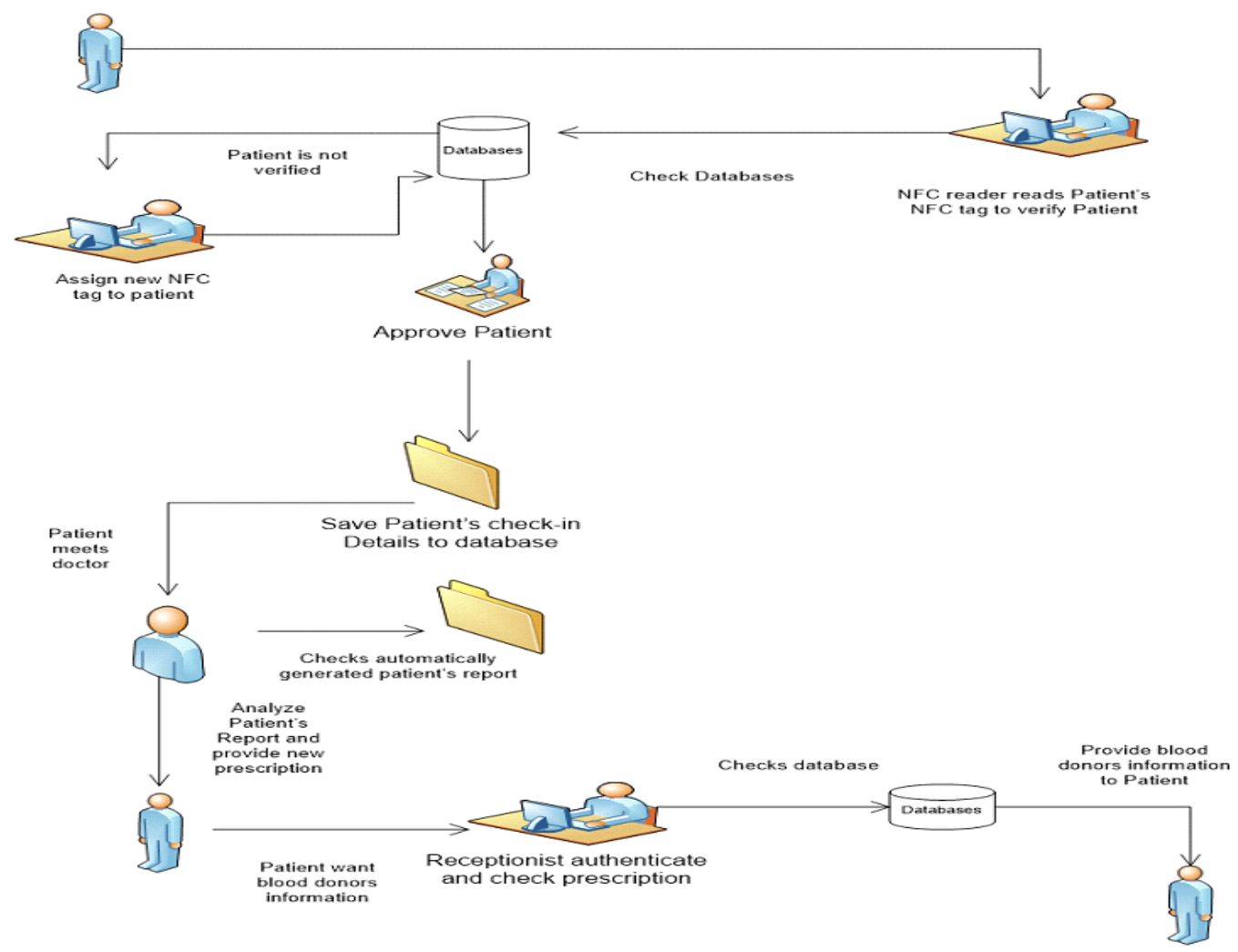

Fig.1. Basic Flow of System
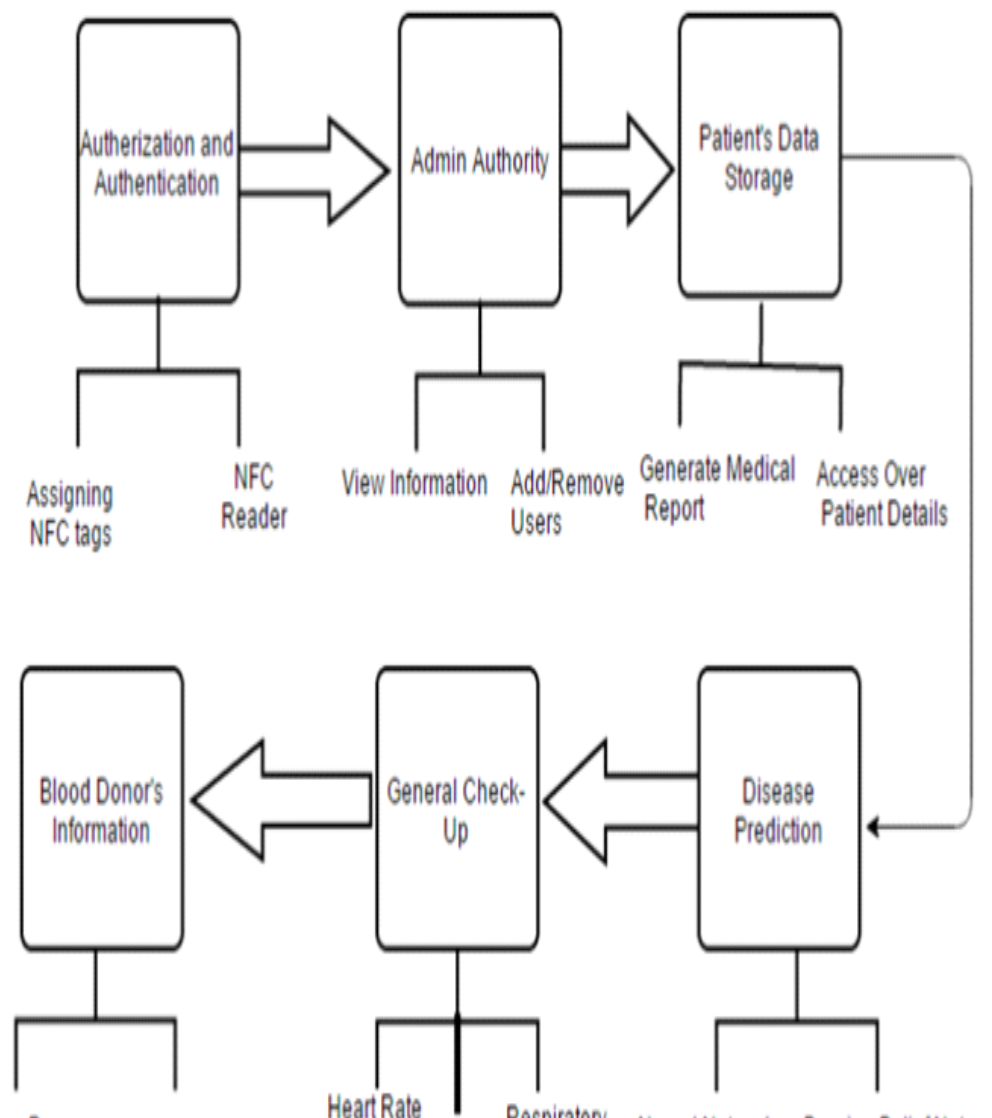

AddNiew Donor SearchDelete Donor

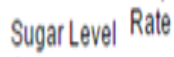

Cholesterol Level

Fig.2. Overall System Diagram 


\section{(C). Authentication Using NFC}

The reader used in our system is ACR $122 \mathrm{U}$ and NFC tag type 2 is used for authentication. These tags are both $\mathrm{read} / \mathrm{write}$ enabled. The API used for this purpose is SmartCard API, which provides functions for both read and write operations, but at a time the device can only be in one mode i.e. either in read mode or in write mode

The process of authentication is carried out through the tag of the user i.e. whenever a tag is brought into the vicinity of the reader, it detects the tag and checks it's content to see whether the user's id is present in the database or not. If the user is not authenticated than the admin assigns him/her a new id, which means that, this id is written in the tag's content.

When the same user visits the healthcare center again, the reader reads the id stored in the tag and the user gets authenticated. This way the system provides to be more reliable and efficient.
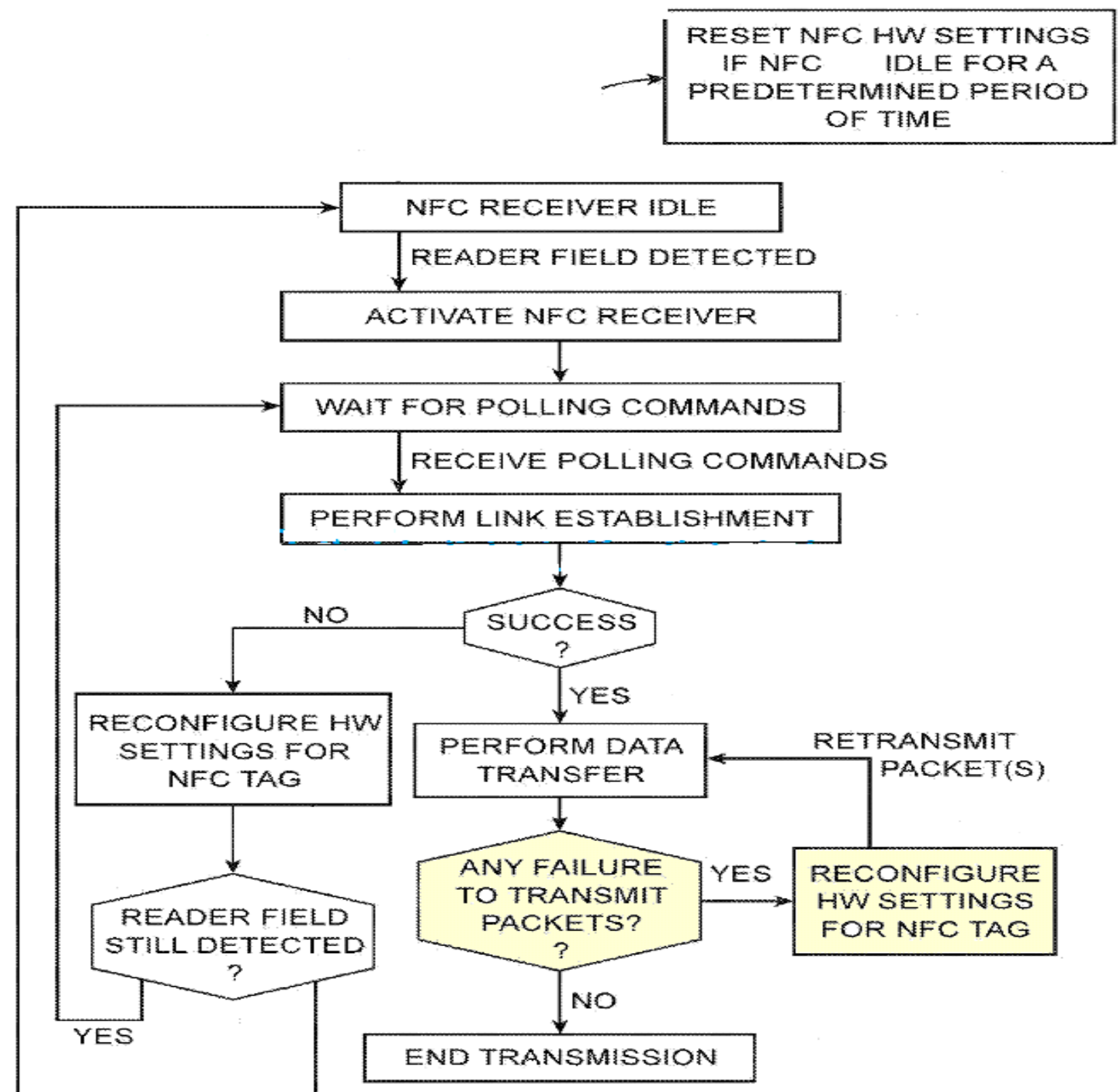

Fig.3. Flow Chart of NFC Read/Write Operation 


\section{(D). Specifications of ACR $122 U$}

The ACR 122U Reader is PC-linked contactless smartcard reader/writer developed based on the 13.56 $\mathrm{MHz}$ contactless RFID technologies. It supports all four types of NFC tags.

ACR $122 \mathrm{U}$ is complaint with PC/SC. Thus, it's a plug and play USB device allowing interoperability with different devices and applications.

With an Access Speed of up to $424 \mathrm{Kbps}$ and a full USB speed of up to $12 \mathrm{Mbps}$, ACR $122 \mathrm{U}$ can read and write quickly and efficiently. The proximity operating distance of the reader is up to $5 \mathrm{~cm}$, depending on the type of contactless tag in use.

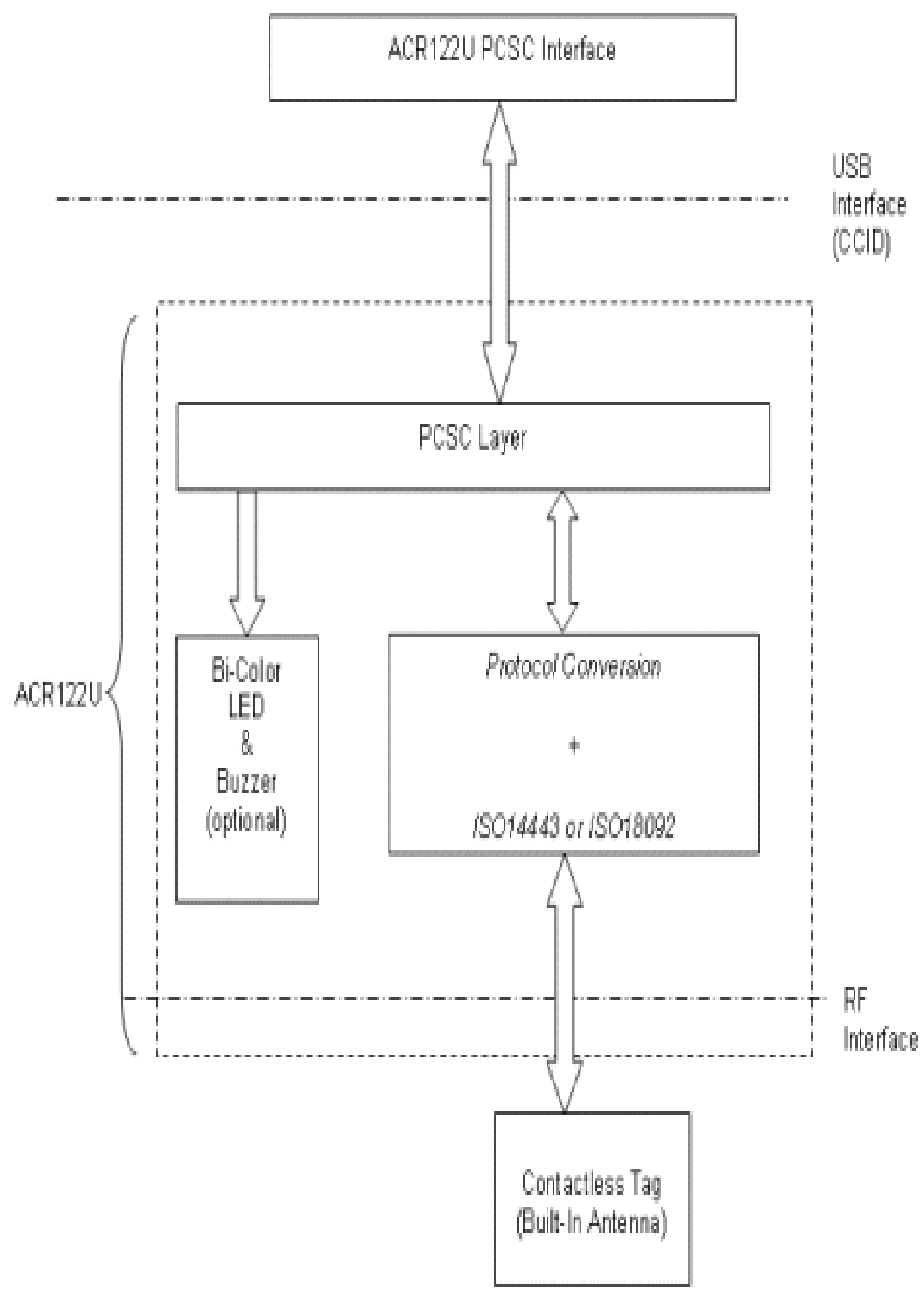

Fig.4. Communication Flow Chart of ACR 122U 


\section{(E.) Disease Prediction}

Our proposed system makes use of ANN, DT and $\mathrm{BBN}$ for the prediction of 10 diseases namely Diabetes, Asthma, Measles, Pneumonia, Typhoid, Jaundice, Appendicitis, Polio, Malaria and Cholera. The possible symptoms of these diseases were selected from some famous publications and later on a cardiologist of Benazir Bhutto Hospital approved them. After careful analysis of the selected parameters, assembling and training of these algorithms were done in Asp.net.

Table 1. Diseases Along with Their Symptom and Priorities Predict by the System

\begin{tabular}{|c|c|c|c|}
\hline Disease & Symptoms & Priority & Recommended Tests \\
\hline Diabetes & $\begin{array}{l}\text { Excessive thirst } \\
\text { Urination } \\
\text { Fatigue } \\
\text { Weight Loss } \\
\text { Increased Hunger }\end{array}$ & $\begin{array}{l}\text { Highest } \\
\text { Highest } \\
\text { Highest } \\
\text { Least } \\
\text { Least }\end{array}$ & $\begin{array}{c}\text { Blood Sugar Random (BSR) } \\
\text { Blood Sugar Fasting (BSF) } \\
\text { Urine R/E }\end{array}$ \\
\hline Measles & $\begin{array}{c}\text { Body Rash } \\
\text { Fever (above } 100^{\circ} \text { ) } \\
\text { Conjunctivitis } \\
\text { Cough } \\
\text { Fatigue } \\
\end{array}$ & $\begin{array}{l}\text { Highest } \\
\text { High } \\
\text { Medium } \\
\text { Least } \\
\text { Least }\end{array}$ & Blood CP \\
\hline Pneumonia & $\begin{array}{c}\text { Fever } \\
\text { Cough } \\
\text { Shortness of Breath } \\
\text { Shaking Chills } \\
\end{array}$ & $\begin{array}{l}\text { Highest } \\
\text { High } \\
\text { High } \\
\text { Medium } \\
\end{array}$ & $\begin{array}{l}\text { Blood CP/ESR } \\
\text { Chest X-Ray }\end{array}$ \\
\hline Asthma & $\begin{array}{l}\text { Shortness of Breath } \\
\text { Cough } \\
\text { Fatigue }\end{array}$ & $\begin{array}{l}\text { Highest } \\
\text { Highest } \\
\text { Highest }\end{array}$ & $\begin{array}{c}\text { Chest X-Ray } \\
\text { Blood CP/ESR } \\
\text { Lung Function Test }\end{array}$ \\
\hline Typhoid & $\begin{array}{c}\text { Fever }\left(103^{0}-104^{0}\right) \\
\text { Abdominal Tenderness } \\
\text { Gastric Issue } \\
\text { Headache } \\
\text { Rose-colored Body Rash }\end{array}$ & $\begin{array}{l}\text { Highest } \\
\text { Highest } \\
\text { High } \\
\text { High } \\
\text { Medium }\end{array}$ & Typhoid Test (Blood, Stool, Urine Samples) \\
\hline Jaundice & $\begin{array}{l}\text { Yellow Eyes } \\
\text { Pale Skin } \\
\text { Tongue Tip Pale } \\
\text { Weather } \\
\text { Dark Urine }\end{array}$ & $\begin{array}{l}\text { Highest } \\
\text { Highest } \\
\text { Highest } \\
\text { Highest } \\
\text { Highest }\end{array}$ & $\begin{array}{c}\text { Liver Function Test } \\
\text { Blood CP } \\
\text { Ultrasound Abdomen } \\
\text { BLI Investigations (Urine Sample) }\end{array}$ \\
\hline Appendicitis & $\begin{array}{c}\text { Pain Near Navel, Right Abdomen } \\
\text { Painful Urination } \\
\text { Pain While Moving } \\
\text { Fever }\left(100^{0} \text { or above }\right) \\
\end{array}$ & $\begin{array}{l}\text { Highest } \\
\text { Highest } \\
\text { Highest } \\
\text { Medium }\end{array}$ & $\begin{array}{l}\text { Blood CP } \\
\text { Abdominal X-ray } \\
\text { CT Scan }\end{array}$ \\
\hline Polio & $\begin{array}{c}\text { Fatigue } \\
\text { Limbs Pain } \\
\text { Body Stiffness } \\
\text { Temperature }\end{array}$ & $\begin{array}{l}\text { Highest } \\
\text { Highest } \\
\text { Highest } \\
\text { Medium }\end{array}$ & $\begin{array}{c}\text { BLI Investigation (Throat Secretions, Stool) } \\
\text { Cerebrospinal Fluid Test }\end{array}$ \\
\hline Malaria & $\begin{array}{c}\text { Fever } \\
\text { Chills } \\
\text { Weather (Summers) } \\
\text { Nausea } \\
\text { Headache } \\
\text { Sweats } \\
\text { Fatigue }\end{array}$ & $\begin{array}{l}\text { Highest } \\
\text { Highest } \\
\text { Highest } \\
\text { Medium } \\
\text { Medium } \\
\text { Medium } \\
\text { Medium }\end{array}$ & $\begin{array}{c}\text { Blood Test (Thick Smear, Thin Smear Test) } \\
\text { BLT's }\end{array}$ \\
\hline Cholera & $\begin{array}{c}\text { Loss Of Skin Elasticity } \\
\text { Muscle Cramps } \\
\text { Loose Motion } \\
\text { Weather (usually in summers) } \\
\text { Low BP } \\
\text { Temperature }\left(100^{0}-102^{0}\right)\end{array}$ & $\begin{array}{l}\text { Highest } \\
\text { Highest } \\
\text { Highest } \\
\text { High } \\
\text { Medium } \\
\text { Medium }\end{array}$ & $\begin{array}{l}\text { Blood Cultured Test } \\
\text { Stool R/E }\end{array}$ \\
\hline
\end{tabular}




\section{(a) Neural Network}

Feed Forward network has been used for this purpose and the network was trained using back propagation algorithm. The network consists of 3 layers, in our proposed system the input layer consisted of symptoms of the disease, 2 hidden layers were used and one output layer: symptoms were provided to the input layer, randomly weights were assigned in the hidden layer and the output layer showed the predicted disease and the corresponding recommended tests for it. Taking the example of Asthma here; after discussing the symptoms of Asthma with the Doctor we came up with some of the possible combinations of these symptoms which might increase the chances of Asthma in a patient and then we assigned a target value to it, after that a target value was assigned to those symptoms which might lead to Asthma but the chances are low. For testing of this network, we fed the input layer with some of the symptoms and it correctly predicted the disease and showed whether the chances of having Asthma were high or low.

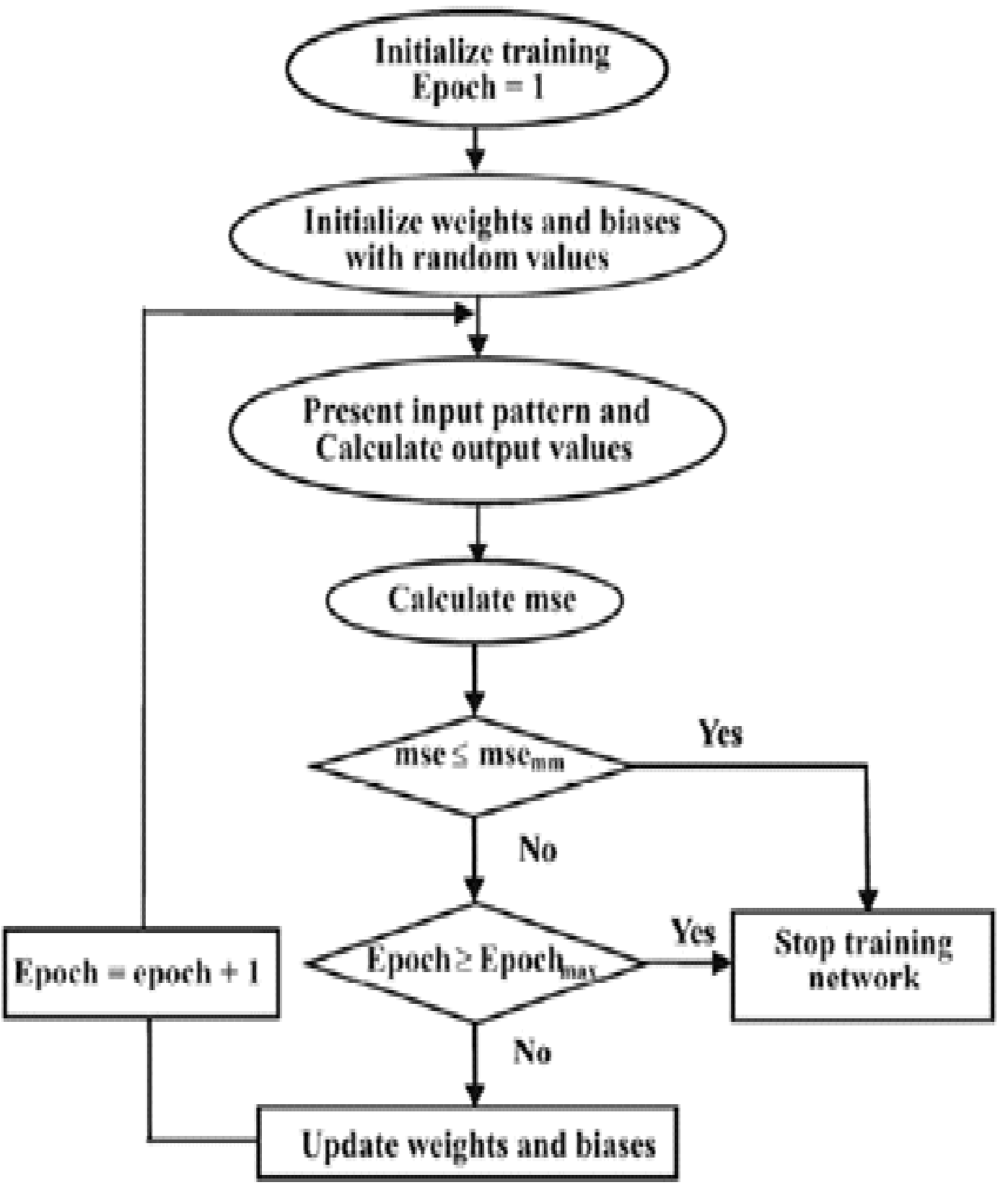

Fig.5. Flow chart of Neural Network 


\section{(b) Bayesian Belief Network}

BBN code contains four main classes: Symptoms, Disease Symptom Map, SCount and Probability Map. Symptom class maps symptoms along with their priorities. Disease Symptom Map contains definition of probability rank, symptoms, diseases and their recommended tests. Scount class counts for symptom occurrence in each and every disease. Lastly, Probability Mapclass calculates probability using a formula in which occurrence of symptom in a disease is divided by the total chosen symptoms, thus giving the results. BBN predicts results based on conditionality probabilities as well. For example doctor chose Cough symptom that appears in more than one disease (Measles, Asthma). The BBN algorithm will consider each disease priority. In measles priority of cough is least whereas, in asthma cough priority is highest so chance of having asthma will be higher than measles.

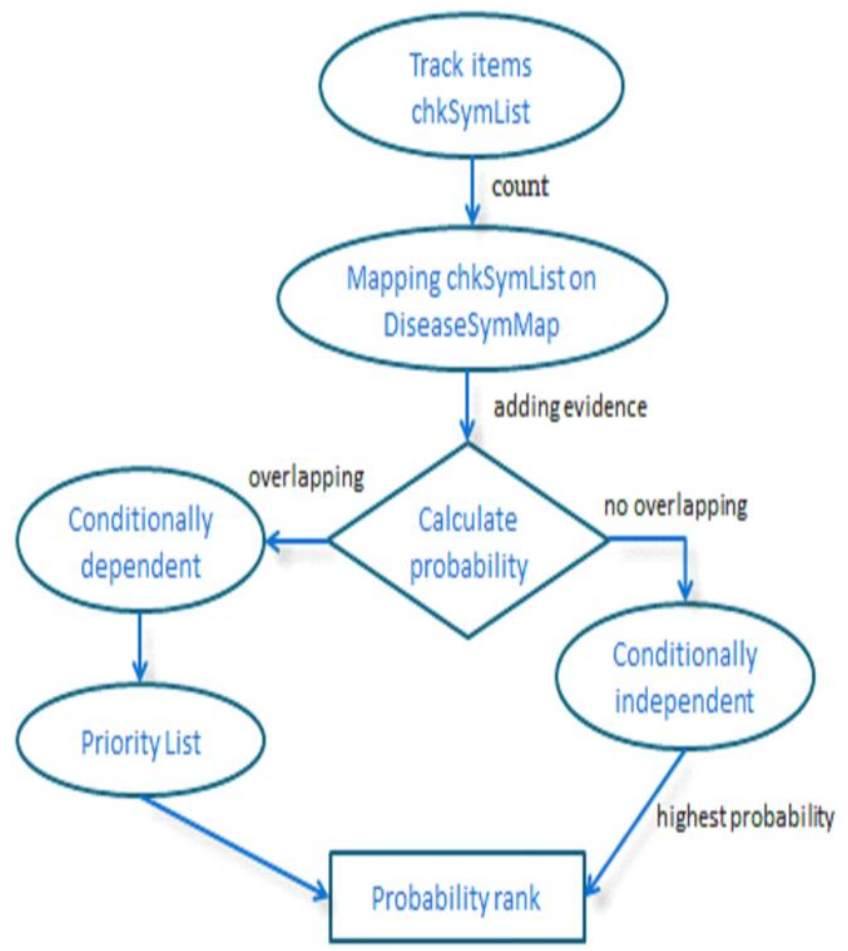

Fig.6. Flow Chart of Bayesian Belief Network

\section{(F). Blood Donor Information}

In our proposed system Blood donor information has been stored in database. In health care for the ease of patient the stored information can be easily retrieved so they can check available donor's information. We have taken donor's information from Benazir Bhutto Hospital and stored all information i.e. Donor's name, CNIC, Blood Group, contact numbers and status in database and give this authority to admin that he/she can check information for any patient. Admin can update, delete and search donor

Table 2. Blood Donor Information

\begin{tabular}{|c|c|c|c|c|c|c|}
\hline \multicolumn{7}{|c|}{ Blood Donors Information } \\
\hline S. \# & Name & DOB & CNIC & Contact No. & Address & $\begin{array}{l}\text { Blood } \\
\text { Group }\end{array}$ \\
\hline 1. & ZeeshanMehmood & $2 / 10 / 91$ & $37405-4293346-5$ & 03218593881 & DhokMatkial,Rwp & $\mathrm{B}+$ \\
\hline 2. & Qasim Mehmood & $3 / 7 / 89$ & 37403-8193264-7 & 03125001543 & KotliSattian,Rwp & $\mathrm{O}+$ \\
\hline 3. & Hafiz Faheem & $1 / 03 / 85$ & $34203-549358-3$ & 0301541554 & $6^{\text {th }}$ Road,Rwp & $\mathrm{O}+$ \\
\hline 4. & M. Aslam & $2 / 06 / 89$ & 13101-0563048-7 & 03455407670 & Abbotabad, Rwp & $\mathrm{AB}+$ \\
\hline 5. & ZahidMehmood & $8 / 10 / 84$ & $37405-2490203-7$ & 03155307871 & Muslim Town,Rwp & $\mathrm{A}+$ \\
\hline 6. & Usman Hakeem & $27 / 6 / 94$ & 37104-6679983-3 & 03125878901 & Attock & $\mathrm{B}+$ \\
\hline 7. & Mudassir Khan & $2 / 1 / 85$ & 37405-0413011-7 & 03455761456 & Khayaban-e-Sirsyed, & $\mathrm{B}+$ \\
\hline 8. & Rafiqullah & $8 / 11 / 90$ & $37405-2169347-6$ & 03139244925 & MotiBazar,Rwp & B- \\
\hline 9. & M. Attique & $12 / 1 / 88$ & $37405-0296974-1$ & 03475181383 & VPO, Parha & $\mathrm{A}+$ \\
\hline 10. & Shakeel Ahmed & $1 / 7 / 94$ & $37102-6589441-7$ & 01342634774 & Fateh Jang & $\mathrm{B}+$ \\
\hline
\end{tabular}




\section{(G). General Checkup}

The system facilitates doctors to view the general history of patients, their heart rate, respiratory rate, sugar level and cholesterol level. The doctor enters the recent value and the system retrieves the past history and the current value and plots a histogram thus enabling the doctor to better examine the patients. The graphs are plotted along time and the above-mentioned parameters of check-up.

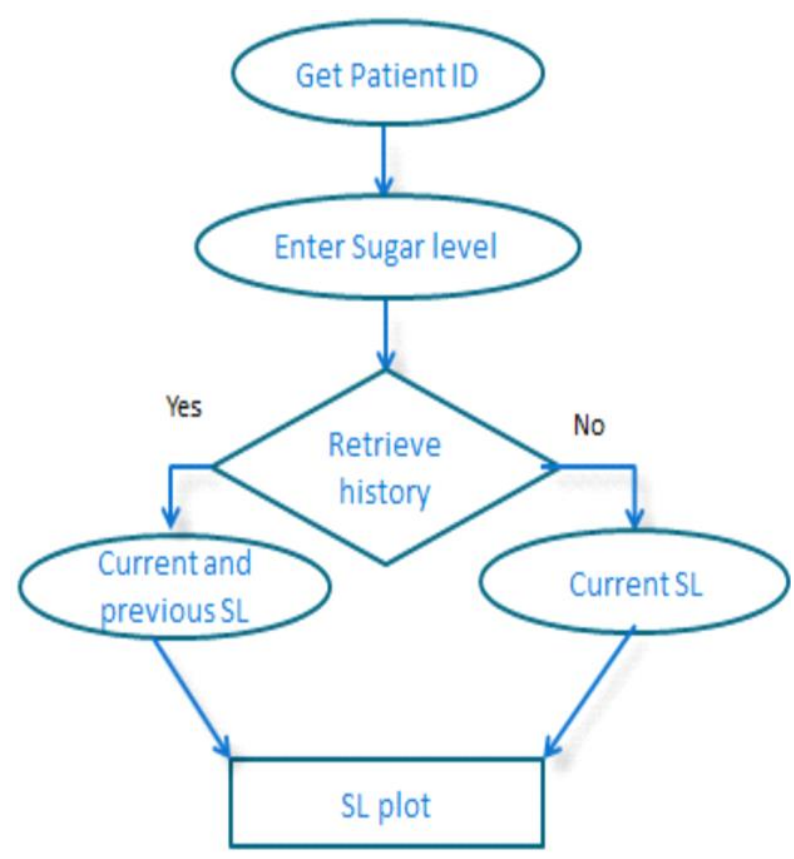

Fig.7. Flow Chart of General Check-Up

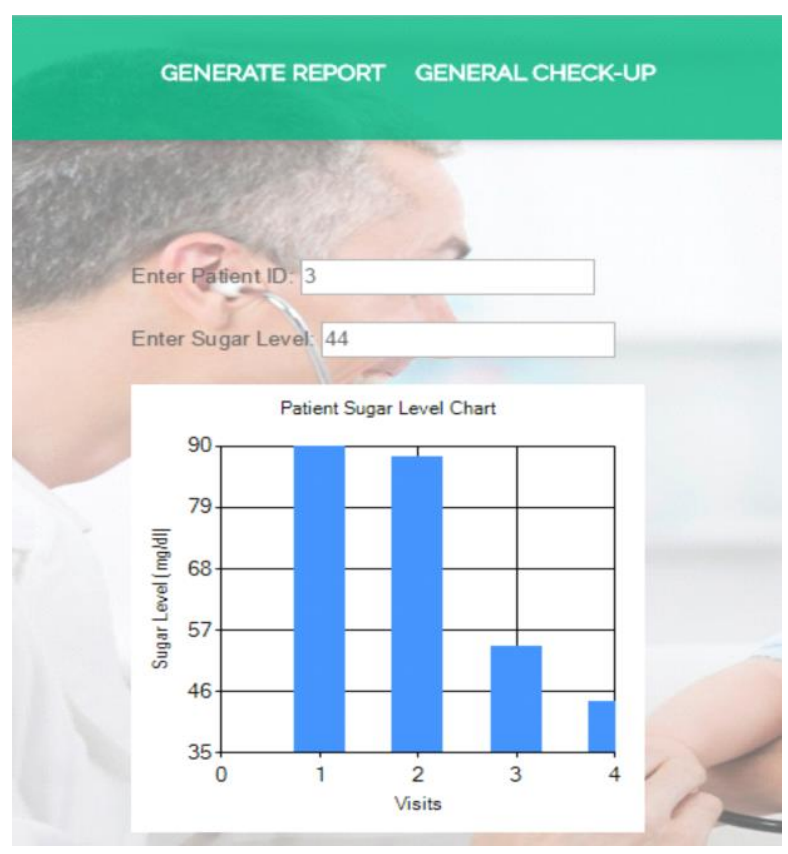

Fig.8. Interface Showing Sugar Level of a Patient

\section{COMPARISON OF NEURAL NETWORK AND BAYESIAN} BELIEF NETWORK

\begin{tabular}{|l|l|}
\hline \multicolumn{1}{|c|}{ NEURAL NETWORK } & BAYESIAN BELIEF NETWORK \\
\hline Non-linear models & Acyclic graphs \\
\hline Non- probabilistic models & Probabilistic models \\
\hline $\begin{array}{l}\text { Neurons activation determined by } \\
\text { preceding layers }\end{array}$ & $\begin{array}{l}\text { Node are conditionally dependent or } \\
\text { independent }\end{array}$ \\
\hline $\begin{array}{l}\text { Mapping between set of input and } \\
\text { output values }\end{array}$ & Encodes probability distribution \\
\hline Complex training & Resistant to over training \\
\hline
\end{tabular}

\section{ANALYSIS}

Based on the results of some studies and overall Results of the algorithms it can be said that ANN gives better results but if the symptoms of some disease are overlapping e.g. diabetes and measles have overlapping symptoms i.e. Fatigue then in this case ANN will abnormal Results, in this case BBN gives better results when symptoms are overlapping and it predict the disease accordingly.

Another Limitation of ANN is that it requires a lot of training, but once trained it gives the best results, there training of the algorithm is directly proportional to the accuracy of the results. While testing BBN we've noticed that if and only if the inputs are provided to it then it predicts a number of diseases and rather than helping the doctor in taking decision it would confuse him. There are some scenarios in which patient processes more than one disease then in such a scenario BBN would be better to use as It calculates the probability of all those diseases that might be processed by a patient after carefully analyzing the symptoms provided to it, another advantage of ANN over BBN is that results provided by it are more readable and understandable as compared to the results of $\mathrm{BBN}$.

$\mathrm{BBN}$ is more reliable for the overlapping symptoms because it mainly works over conditional dependencies and calculates the prob. of all those diseases containing the overlapping symptom and represents out as 1 st chance of disease 2 nd probability of disease and so on.

Consider a scenario in which doctor after examining the patient enters 'cough, fatigue, shortness of breath'. These symptoms will be compared along all the 29-30 symptoms of 10 diseases. Whenever a match will be found the count of correct disease will increase by one. Then the algorithm will work over calculating probabilities; two cases can be there end nodes acting as conditionally independent and edges as conditional dependent state. The conditionally independent nodes give the disease name having highest probability of occurrence. But if there is overlapping symptoms i.e. according to disease data record cough and shortness of breath exist in asthma and pneumonia both and fatigue exists for pneumonia and measles. In this case a list of diseases based on symptom's priority (highest, high, 
medium, least) will be formed. The disease containing the highest priority symptoms will be marked as most likely chances of occurrence in a patient according to input entered by doctor it will be asthma (2.77) and the one with second highest values will be called as second probability and chances are, patient is having that disease as well i.e. pneumonia (1.33) and so on. BBN helps in giving more than one outputs.

However, one thing should be kept in mind these algorithm results are not all forced as final words of doctor, it is just a helping tool saving doctors time and providing them support for making decision. We are not at all challenging doctor's medical knowledge.

After analysis of our system it is concluded that in some cases ANN give better results while in some cases $\mathrm{BBN}$ proved to be better so the choice of algorithm to be used in health care depends on the scenario.

\section{FUTURE WORK}

In future the system can be enhanced by including some major disease prediction module e.g. cancer and heart diseases. RFID based NFC tags can be utilized for storing the medical history instead of only patient's ID. Enabling patients for self-examine by providing disease related questionnaire and tracing for up to date blood donor providers.

Although basic disease prediction has been done in our proposed system but including some major disease prediction will prove to be more beneficial for the doctors. Also portable devices and wristbands having NFC can be used in upcoming years to cater mobility of the patients.

\section{CONCLUSION}

In our proposed system users are efficiently authenticated. It also helped the doctors in taking decisions by using the disease prediction module of the system in which results of 2 algorithms are compared to analyze which one is the best to be used in healthcare centers.

This system is not just confined to developed hospitals but is more useful for rural areas where doctors timely availability is always a question. Nurses and scouts can use our proposed disease prediction module. It is a LAN application that can be easily embedded at personal computers. Proposed system is made cost-effective; integrated on a desktop instead of smart phone because in Pakistan everyone can't afford a smart phone.

\section{REFERENCES}

[1] A. Devendran et al. (2012, May). Mobile Health Care System Using NFC Technology $\left(9^{\text {th }}\right.$ ed.) [Online]. Available: http://ijcsi.org/papers/IJCSI-9-3-3-428-431.pdf

[2] A. Prinz et al. (2012, September). Electronic Data Capture in Health Care- NFC as Easy Way for Selfreporting Health Status Information $\left(1^{\text {st }}\right.$ ed) [Online]. Available:
http://www.healthpolicyandtechnology.org/article/S2211$8837 \% 2812 \% 2900057-3 /$ abstract

[3] N. Rahman et al. (2013). Malaysia Hospital Asset Tracking System using RFID Technology (MHATS) [Online]. Available:

http://www.researchgate.net/publication/256187264_Mal aysia_Hospital_Asset_Tracking_System_using_RFID_Te chnology_\%28MHATS\%29

[4] A. Krishna et al. (2013, April). NFC-based Hospital Realtime Patient Management System (4 $4^{\text {th }}$ ed) [Online]. Available: http://www.ijettjournal.org/volume-4/issue4/IJETT-V4I4P225.pdf

[5] T. Cerlinca et al. RFID-based Information System for Patients and Medical Staff Identification and Tracking [Online]. Available: http://cdn.intechopen.com/pdfswm/8502.pdf

[6] A.Devendran and Dr. Bhuvaneswari. (2012, January 1).Mobile Healthcare-Proposed NFC Architecture [Online]. Available:

www.ijsrp.org/research_paper_jan2012/ijsrp-jan-201261.pdf

[7] D. Peter et al. (2012). The Integration of Ontologies and RFID NFC in Healthcare [Online]. Available: www98.griffith.edu.au/dspace/bitstream/10072/49250/1/8 3083_1.pdf

[8] K. Harald et al. (2013, January 18). Developing a NFC Based Patient Identification and Ward Round System for Mobile Devices Using the Android Platform [Online]. Available:

http://www.researchgate.net/publication/261025626_Dev eloping_a_NFC_based_patient_identification_and_ward_ round_system_for_mobile_devices_using_the_android_pl atform

[9] Ekahau. (2013).The ROI of Real-Time Location Systems and Active RFID in Healthcare [Online]. Available: http://www.ekahau.com/real-time-locationsystem/technology

[10] M. Adam et al. Using NFC-enabled Mobile Phones forHealth in Developing Countries [Online]. Available: http://web.media.mit.edu/ lfgs/papers/nfc09-mit-ird.pdf

[11] Tobias et al. (2013). A NFC-based Concept for Medication Related Patient Services [Online]. Available: http://ieeexplore.ieee.org/xpl/abstractAuthors.jsp?reload= true\&arnumber $=6525247$

[12] S.Günter et al. (2013). Near Field Communication Technology based mHealth for Telemonitoring of Patients with Chronic Diseases [Online]. Available: http://embc.embs.org/files/2013/1825_FI.pdf

[13] I. Rebeca et al. (2012, may 17). A Review of Automatic Patient Identification Options for Public Health Care Centers with Restricted Budgets [Online]. Available: http://www.ncbi.nlm.nih.gov/pmc/articles/PMC3615806/

[14] June-Suh Cho, (2013, April). Efficient Healthcare Process Based on Ubiquitous Technology [online]. Available: http://www.ijsrms.com/media/1n4IJSRMS0103310_v1_is4_109-117.pdf.

[15] P. Kiran et al. (2014, April). NFC+ Android Application by using NFC technology for Hospital Management System (P.kiran et al) [Online]. Available: http://www.ijrat.org/downloads/april-2014/paper\%20id24201494.pdf. 


\section{Authors' Profiles}

Arshia Zaffar, graduated software engineer from Pakistan, capable of exploring new horizons in various research domains. Arshia did her internship at PTCL and successfully published research paper "A survey based study for QoS multicasting in mobile ad-hoc networks" at ijccse, in year, 2014. Her thesis work is available at LAP (Lambert Academic Publishing), published in year, 2016.

Mahnoor Gul was born in Rawalpindi on 17th Feb, 1994. Mahnoor has recently completed her bachelor's degree in software engineering from Pakistan in the year 2015. In the year 2013, she did her 3 months internship at PTCL. Her first survey paper got published in the year 2014 titled as "Integration of Quality Assurance in Extreme Programming".
Rida Mumtaz, was born in Rawalpindi on $30^{\text {th }}$ Oct, 1992. Rida successfully graduated from Pakistan in the year 2015 and now holds a bachelor's degree in software engineering. She completed her 3 months internship at PTCL in the year 2013. Her survey paper under the title "A survey based study for QOS multicasting in mobile ad-hoc networks" got published in the year 2014.

Aliya Ashraf Khan has completed her MS Software Engineering from National University of Science \& Technology, Islamabad Pakistan and doing her Phd in Computer Software Engineering from the same university. Currently she is working as Lecturer in Department of Software Engineering, Fatima Jinnah Women University Rawalpindi, Pakistan. Her area of research includes Human Computer interaction and its applications, Digital Image processing and Artificial Intelligence.

How to cite this paper: Arshia Zaffar, Mahnoor Gul, Rida Mumtaz, Aliya Ashraf Khan,"Development of Decision Support System for Health Care Consultation using RFID Based NFC Tags for Patient Identification", International Journal of Information Engineering and Electronic Business(IJIEEB), Vol.8, No.3, pp.20-30, 2016. DOI: 10.5815/ijieeb.2016.03.03 